\title{
Una ciudad paralizada. La huelga general del verano de 1934 en Jerez de la Frontera
}

\section{DIEGO CARO CANCELA Universidad de Cádiz}

La Segunda República es, junto con el sexenio democrático (1868-1874) y el mal llamado "trienio bolchevique" (1918-1920), uno de los períodos de mayor conflictividad social de la historia contemporánea de España.

El cambio de régimen, con el amplio sistema de libertades que abrió, las repercusiones de la crisis del 29 en el mundo del trabajo y el crecimiento de las organizaciones obreras de clase (UGT y CNT), fueron, entre otros, factores que crearon un clima de agitación social que tuvo amplias y variadas manifestaciones: desde la huelga general al boicot, pasando por el lock-out patronal, el atentado o los incendios intencionados.

En el caso concreto de la provincia de Cádiz, tres circunstancias favorecían el desarrollo de la conflictividad. En primer lugar, la existencia de una gran extensión de latifundios - la primera de España en términos relativos-, que mantenía una estructura de clases tremendamente desigual, porque mientras que un reducido número de propietarios poseía la mayor parte de la superficie cultivable, enfrente, un amplio "ejército" de jornaleros pasaba parte del año desempleado y cuando trabajaba lo hacía por unos salarios de hambre.

Por otra parte, en Cádiz la CNT era la primera fuerza sindical de la provincia, multiplicando por cuatro su número de afiliados entre 1931 y 1936 (1), mientras que la UGT aquí tenía la implantación más baja de toda Andalucía. Parece fácil explicar el masivo seguimiento que las acciones sindicales y las huelgas generales promovidas por el anarcosindicalismo tuvieron en los distintos municipios gaditanos a lo largo de la Segunda República.

(1) Pasa de 11.797 afiliados en 1931 a 45.323 en 1936. 
Por último, un tercer hecho contribuyó también a encrespar todavía más los conflictos sociales: la abierta intransigencia y las posiciones marcadamente reaccionarias de la patronal y los grupos conservadores de la provincia -localizados alrededor del eje Cádiz-Jerez-, vinculados políticamente en su casi totalidad, durante el período republicano, a la CEDA y otras formaciones de corte autoritario, como Renovación Española o la propia Falange (2).

Debido a todas las circunstancias anteriormente expuestas, la provincia de Cádiz vivió en la Segunda República una agitación social de múltiples manifestaciones.

En un reciente trabajo, por ejemplo, utilizando fuentes hemerográficas, hemos cuantificado el número de huelgas realizadas entre abril de 1931 y julio de 1936, duplicando a través de esta investigación los resultados proporcionados hasta ahora por otros historiadores basados en las estadísticas del propio Ministerio de Trabajo.

\section{CUADRO I. HUELGAS EN LA PROVINCIA DE CÁDIZ (1931-1936)}

\begin{tabular}{lccccccc} 
& 1931 & 1932 & 1933 & 1934 & 1935 & 1936 & \\
\cline { 2 - 8 } & 12 & 19 & 40 & 35 & 1 & 21 & 128 \\
M. de Trabajo (3) $_{\text {Diego Caro Cancela (4) }}^{42}$ & 52 & 36 & 55 & 3 & 23 & 211
\end{tabular}

En este marco espacial de luchas obreras, la ciudad de Jerez de la Frontera tuvo una destacada presencia a lo largo del régimen republicano, siendo - como se observa en el Cuadro II-, la población que concentra casi el 20 por ciento del movimiento huelguístico provincial. Pero es que, además, en esta ciudad del vino tuvieron lugar algunos sucesos que mostraban palpablemente el ambiente de tensión social que en momentos concretos se padeció. A veces con formas un tanto extrañas, como ocurre el 7 de julio de 1931, cuando un aeroplano desconocido arrojaba un artefacto incendiario sobre un rastrojo, quemando 150 aranza-

(2) Sobre la adscripción política de los grupos conservadores gaditanos en la $\mathrm{II}^{2}$ República: CARO CANCELA, D.: La Segunda República en Cádiz: elecciones y partidos políticos. Cádiz, 1987.

(3) Citado por A.M. CALERO en Movimientos sociales de Andalucía (1820-1936). Madrid, 1976, p. 89.

(4) CARO CANCELA, D.: «Una aproximación cuantitativa a los conflictos obreros en la provincia de Cádiz durante la Segunda República" en "Cádiz en su Historia. V Jornadas de Historia de Cádiz». Cádiz, 1987, pp. 121-135. Se han utilizado como fuentes tres periódicos de Cádiz capital: "Diario de Cádiz»; "La Información» y "El Noticiero Gaditano». 
das de trigo y 50 de cebada en la finca de Vico Majarromaque (5). En otras ocasiones los destrozos intencionados se producían con motivo de algún conflicto laboral, como ocurre, por ejemplo, durante la huelga agrícola de la campiña, en el verano de 1933, cuando sólo en el término de Jerez se queman 11 pajares y se destruyen 8 máquinas segadoras (6), mientras dura la misma. Y no faltaba la agresión violenta con bomba, como la que estalla en la casa del diputado radical jerezano Fermín Aranda, a principios de enero de 1933 (7), la que causa 5 heridos en el Casino Jerezano, poco tiempo después (8), o la que estalla en el verano de este mismo año en el Registro de la Propiedad (9).

Estos sucesos no deben causar extrañeza en una ciudad con un movimiento obrero de larga tradición reivindicativa (10) y una patronal que, como la Asociación Gremial Agraria jerezana, no tenía ningún reparo en amenazar, en el verano de 1931, al Gobierno, con no sembrar sus campos si se le impedía la recolección de la cosecha a máquina (11).

\section{CUADRO II. HUELGAS EN JEREZ (1931-1936)}

\begin{tabular}{ccccccc}
1931 & 1932 & 1933 & 1934 & 1935 & 1936 & Total \\
\hline 7 & 9 & 11 & 8 & - & 7 & 42
\end{tabular}

Fuente: «Diario de Cádiz», «La Información» de Cádiz y "El Noticiero Gaditano».

Claramente hegemonizado por el sindicalismo anarquista de la CNT, el obrerismo jerezano de la Segunda República se va a caracterizar por presentar una elevada tasa de sindicación y por encontrarse fuertemente afectado por las consecuencias de la Gran Depresión del 29, con el 35,77 por ciento de los afiliados a sociedades obreras en paro en 1932, según puede apreciarse en el Cuadro III.

(5) Archivo Histórico Nacional. Telegrama de fecha 7 de julio de 1931 que remite al gobernador civil el capitán de la Guardia Civil del puesto de Jerez. Legajo 6 A. Expediente 3 .

(6) «Diario de Cádiz» (en adelante DC) (18-VI-1933), edición mañana.

(7) Ibídem (11-I-1933), edición mañana.

(8) Ibídem (27-II-1933).

(9) Ibídem (25-VII-1933).

(10) Sobre la historia del movimiento obrero jerezano existe una amplia y desigual bibliografía. Para el primer tercio del siglo XX: MAURICE, J.: «Campesinos de Jerez (1902-1933)", en Estudios de Historia Social, núm. 10-11. Madrid, 1979, pp. 61-114. (11) Archivo Histórico Nacional Sección Gobernación. Legajo 6 A. Exp. 3, telegrama de fecha 10-VII-1931. 
Adscritas claramente al sindicato cenetista estaban algunas de las sociedades obreras más importantes (viticultores, agricultores, carpinteros, albañiles o panaderos), con dirigentes de larga experiencia reivindicativa, como José Ballesteros, Diego Martínez o Sebastián Oliva, este último principal figura del movimiento obrero jerezano y del periódico "La Voz del Campesino".

\section{Cuadro III. Sociedades obreras jerezanas en 1932}

\begin{tabular}{|c|c|c|c|}
\hline & Afiliados & $\begin{array}{l}\text { Afiliados } \\
\text { en paro }\end{array}$ & Ratio \\
\hline Albañiles «La Constructora» & 475 & 211 & 44,42 \\
\hline Viticultores & 1.500 & 700 & 46,66 \\
\hline Albañiles, peones y similares CNT & 1.500 & 500 & 33,33 \\
\hline Constructores de envases & 100 & 12 & 12 \\
\hline Molineros y cargadores & 158 & 58 & 36,70 \\
\hline Oficios varios & 620 & 160 & 25,80 \\
\hline Agricultores & 4.143 & 2.000 & 48,27 \\
\hline Metalúrgicos & 572 & 70 & 12,23 \\
\hline Carpinteros & 342 & 98 & 28,65 \\
\hline Vidrieros & 340 & 259 & 76,17 \\
\hline Constructores automóviles & 397 & 48 & 12,09 \\
\hline Pintores & 110 & 39 & 35,45 \\
\hline Empleados de escritorios & 465 & 42 & 9,03 \\
\hline Jardineros & 100 & 10 & 10 \\
\hline Litógrafos & 80 & 15 & 18,75 \\
\hline Limpieza pública & 60 & 10 & 16,66 \\
\hline Confiteros & 40 & 10 & 25 \\
\hline Profesores de orquesta & 80 & 25 & 31,25 \\
\hline Toneleros & 420 & 250 & 59,52 \\
\hline Barberos & 98 & 25 & 25,51 \\
\hline Cocineros & 40 & 12 & 30 \\
\hline Horticultores & 120 & 60 & 50 \\
\hline Electrogasistas & 120 & 9 & 7,5 \\
\hline Constructores de calzados & 100 & 21 & 21 \\
\hline Aserradores mecánicos & 150 & 12 & 8 \\
\hline Cerámicos & 54 & 11 & 20,37 \\
\hline Conductores de carro & 100 & 23 & 23 \\
\hline Artes gráficas & 135 & 10 & 7,40 \\
\hline Camareros «Unión jerezana» & 250 & 40 & 16 \\
\hline Arrumbadores & 1.045 & 500 & 47,84 \\
\hline Panaderos & 400 & 50 & 12,5 \\
\hline
\end{tabular}


Dependientes de comercio

Empleados del Ayuntamiento

Camareros "Los Gastronomistas"

Dependientes de teatro asociados

Expendedores de pescado "La Liga"

Expendedores de pescado «La Unión

Ferroviarios sección Jerez

TOTAL

\begin{tabular}{rrc}
300 & 25 & 8,33 \\
150 & - & - \\
18 & 18 & 100 \\
24 & 6 & 25 \\
44 & - & - \\
14 & - & - \\
260 & - & - \\
14.924 & 5.339 & \\
\hline
\end{tabular}

Fuente: Archivo Municipal de Jerez de la Frontera. Legajo 289, citado por J. MAURICE: op. cit., pp. 104-105.

Más cercano al sindicato ugetista se encontraban los trabajadores de las bodegas, como los toneleros, con un periódico - "El Martillo"- de larga tradición, o los arrumbadores, mientras que era más ambigua y difusa la vinculación de otras profesiones y asociaciones.

En este entorno socioeconómico se produce la huelga general que a finales del verano de 1934 paraliza Jerez y que vamos a comentar en este trabajo, por tres motivos. Por un lado, porque se trata de un movimiento huelguístico prácticamente desconocido hasta hoy en la historiografía social más reciente. En segundo lugar, porque cierra un ciclo tremendamente conflictivo en la ciudad, que se inicia con la proclamación del nuevo régimen republicano el 14 de abril de 1931 y que no reaparece hasta después del 16 de febrero de 1936, cuando se produce el triunfo del Frente Popular. Y, por último, porque adelanta una alianza entre sociedades ugetistas y cenetistas que más tarde se trasladará al resto del país, poniendo fin a una práctica sindical de marcado enfrentamiento, como la desarrollada en años anteriores.

1934 no es solamente el año de la revolución del octubre asturiano. Es también el de la huelga general campesina dirigida por la FNTT de la UGT, que alcanzó en el verano a 38 provincias y más de 500 pueblos (12) y, a nivel internacional, el año de las grandes huelgas en Estados Unidos, de la radicalización de algunos Partidos Socialistas europeos y el comienzo del período de la política del Frente Popular (13).

En el plano político, 1934 es en España el comienzo de los gobiernos de coaliciones republicanas basadas en el Partido Radical de Lerroux

(12) TUÑÓN DE LARA, M., Tres claves de la Segunda República. Madrid, 1985, pp. 130-153.

(13) BROUE, P., "Octubre del 34 en el contexto europeo" en el volumen colectivo Octubre 1934. Madrid, 1985, pp. 9-18. 
y apoyados desde fuera por la CEDA, los grandes triunfadores de las pasadas elecciones legislativas de 1933 (14).

En este ambiente de recuperación de las fuerzas conservadoras, con lo que parecía el gran desquite de los patronos agrarios - " ¡Comed república!» (15)-, con las organizaciones obreras ya claramente a la defensiva, estalla en Jerez la huelga general más importante de todas las que vive la ciudad en la Segunda República.

No era la primera del año, porque el 9 de enero de 1934 los arrumbadores jerezanos decidían abandonar el trabajo, ante la colocación de una mujer más en la sección femenina de la casa González Byass, para cubrir una vacante.

Ante esta situación, la patronal decretaba el lock-out, el día 18, quedando despedidos los arrumbadores de todas las bodegas (16). La respuesta obrera no se hizo esperar, porque a los pocos días se declaraba en Jerez una huelga general en solidaridad con los arrumbadores. Según el «Diario de Cádiz» del 29 de enero, en total eran veinte los "gremios» en huelga.

Tiene que intervenir el gobernador civil de la provincia, que dicta un laudo con la intención de arreglar el conflicto, fijando en 64 el número de mujeres que podían trabajar permanentemente en la Casa González Byass, ordenando la readmisión de todos los obreros sin represalias y estableciendo un sistema de compensación de 40 horas extraordinarias de trabajo para hacer frente al pago por la patronal de los salarios de los diez días no trabajados (17).

Sin embargo, los arrumbadores no aceptan estas condiciones; de manera que aunque el 31 de enero se abrían las bodegas, los obreros no acudían al trabajo, por lo que, poco a poco, nuevas sociedades se solidarizan con los huelguistas. A la una de la tarde lo hacían los empleados de Banca, por la noche los empleados de espectáculos — que dejaban a Jerez sin teatro--, de madrugada paraban los panaderos, y hasta los empleados dependientes del comercio, según el corresponsal del «Diario de Cádiz», iban al paro, por vez primera en la ciudad (18).

(14) ROBINSON, R., Los orígenes de la España de Franco. Derecha, República y Revolución, 1931-1936. Barcelona, 1974, p. 248.

(15) TUÑÓN DE LARA, M., La Crisis del Estado: Dictadura, República, Guerra (1923-1939). Tomo IX de la "Historia de España" dirigida por..., Barcelona, 1981, p. 181.

(16) Un resumen de esta huelga en el legajo 3.365 del Archivo Municipal de Jerez de la Frontera, que recoge los documentos de la Delegación Local del Consejo de Trabajo, con los cuestionarios sobre conflictos enviados desde Jerez a la Dirección General de Trabajo.

(17) «La Información», (31-I-1934).

(18) DC (1-II-1934), edición de tarde. 
Por la tarde del 1 de febrero llegaba a Jerez el comisario jefe de Policía de Cádiz, para clausurar todos los centros obreros, a pesar de la ausencia total de incidentes (19).

El 4 de febrero, el sexto día de huelga general, se celebrada una reunión entre seis patronos y seis obreros arrumbadores para acercar posiciones, pero sin resultados, de manera que el gobernador civil tiene que presentar un nuevo laudo, teniendo como referencia el informe del delegado del Ministerio de Trabajo, totalmente favorable a los obreros. Entre otros cosas, obligaba a los patronos al pago de seis días laborables al entrar los arrumbadores al trabajo, a la vez que se prohibía cualquier tipo de represalia por cada parte. Por este motivo, si bien los trabajadores lo aceptan inmediatamente, los patronos tienen que permanecer reunidos hasta altas horas de la madrugada, para al final aceptar lo que vieron como irreversible (20).

En este ambiente de crispación social no faltó la provocación fascista. En la noche del 28 de mayo, uno de sus grupos irrumpía en el local de la sociedad de albañiles, a afectos a la CNT, para - según dijeron- pedir explicaciones sobre un manifiesto publicado en el periódico obrero "La Jarra", en el que se atacaba a uno de los jefes de la Falange local. Después de una discusión se produce un enfrentamiento a tiros que provoca cuatro heridos, todos falangistas, entre los que se encontraba un ex-policía, secretario de José Antonio Primo de Rivera (21).

Al día siguiente, y como respuesta a lo que el mismo gobernador civil calificaba de provocación de la Falange; volvía a declararse otra huelga general, esta vez de 48 horas, suspendiéndose también la salida procesional del Corpus (22). Y el 4 de junio, una comisión de presidentes de sociedades obreras entregaba al alcalde jerezano un pliego de firmas, suscrito por 35 "gremios" representantes de 15.000 afiliados, para protestar por la agresión fascista al local de la Asociación Sindical de Albañiles, Peones y Similares (23):

Esta era la atmósfera que se respiraba en Jerez en el vèrano de 1934, cuando el 8 de agosto los arrumbadores de las bodegas decidían ponerse en huelga, negándose a trabajar con cajas de madera procedentes de otras poblaciones (24). Inmediatamente, la Asociación Gremial de Exporta-

(19) DC (2-II-1934), edición de tarde.

(20) DC (5-II-1934), edición de tarde.

(21) «La Información» (29-V-1934), edición de mañana.

(22) DC (31-V-1934), edición de mañana.

(23) DC (5-VI-1934), edición de tarde.

(24) Archivo Municipal de Jerez de la Frontera. Legajo 3.365. 
dores de Vinos, la patronal del sector, decretaba el lock-out. Al mismo tiempo, se inicia un movimiento de solidaridad con los huelguistas, que se extiende a otras profesiones de la ciudad, como cajoneros, aserradores, toneleros y todos los turnos de vidrieros de la fábrica de botellas, todo ello con la vendimia encima, lo que amenazaba la propia cosecha, y cuando ya se encontraban en huelga, por otros motivos, los obreros de la construcción, los horticultores y los mozos del palenque.

Para desarticular la solidaridad de los trabajadores, lo primero que hace el Gobierno es utilizar el mismo recurso que meses antes había empleado con motivo de la huelga de campesinos promovida por la FNTT: el 27 de agosto, el gobernador civil, después de entrevistarse con el alcalde y la dirección de la patronal de las bodegas, declaraba de utilidad pública la recogida de la cosecha de uva en la provincia de Cádiz (25).

Según el gobernador, Luis de Armiñán, como la raíz del conflicto jerezano estaba en las posiciones intransigentes de los obreros, su obligación era garantizar la libertad de trabajo y el orden en la ciudad, "serenamente esperando que los hombres trabajadores de buena voluntad se acerquen a los poderes con justas demandas".

En una nota que entregaba a "El Guadalete" el 31 de agosto, la postura de la primera autoridad civil de la provincia se manifestaba con toda claridad:

"declarada de utilidad pública la cosecha, declarada la libertad de trabajo, espero que el honrado obrero de Jerez entable conmigo y con los exportadores un diálogó de igual a igual, olvidándose de los postulados de anarquía y de fuerza que no conducen a nada".

Para completar la respuesta gubernamental, un bando de la alcaldía de este mismo día declaraba terminado el lock-out en las bodegas, que debían ser abiertas el sábado 1 de septiembre, dando de plazo hasta las 5 de la tarde del día 3 a todos los trabajadores que quisieran incorporarse al trabajo. Los que no efectuaran la reincorporación podían ser automáticamente despedidos por los bodegueros, que según el bando, tenían capacidad para realizar nuevás contrataciones a fin de cubrir los despidos que se pudieran producir.

La ofensiva patronal también se trasladaba a la prensa, con dos diarios - «El Guadalete» y "El Diario de Jerez» - y un semanario totalmente a su favor. Este último, «Claridad», dirigido por el falangista Julián Pemartín, el 3 de septiembre descalificaba las razones esgrimidas por los arrumbadores para ir a la huelga:

(25) «El Cunadalete" (28-VIII-1934). Diario conservador de Jerez. 
"Se ha tratado entre otras exigencias de imponer restricciones a la libertad patronal para organizar sus industrias en la forma que estime más conveniente. La intervención obrera no puede llegar hasta el extremo de prohibir que se construyan depósitos para el vino si están fabricados con determinados materiales, ni imponer la compra de las cajas construidas en determinadas casas, porque las demás están fabricadas fuera de la localidad.

Todas estas exigencias no hay Gobierno en Europa que las autorice, ni clase patronal que las pueda soportar dignamente, ni economía industrial que las resista".

Con esta situación, a principios de septiembre comenzaban a llegar a Jerez conductores militares de: Sevilla y Cádiz para transportar las botas desde las bodegas hasta las viñas, al mismo tiempo que, ante la negativa de los viticultores de la campiña a realizar la vendimia, los propietarios jerezanos tienen que traer a más de 800 esquiroles forasteros, mientras que el alcalde radical —n plena "guerra" psicológica- declaraba a "El Guadalete" del 8 de septiembre, que estaba recibiendo ofertas de diversos alcaldes de la provincia de trabajadores para la vendimia que sobrepasaban los 400 ó 500 .

No obstante, poco a poco, empiezan a llegar las primeras muestras de solidaridad con los trabajadores jerezanos, desde poblaciones vecinas. Ya el 5 de septiembre, se habían declarado en huelga por este motivo los vendimiadores sanluqueños de una viña de Osborne. El 11 eran los estibadores del puerto de Cádiz los que boicoteaban el trabajo de carga y descarga con los productos de Jerez,' y el 13 eran los arrumbadores, toneleros y viticultores de Chiclana y El Puerto de Santa María, los que decidían ponerse también en huelga por solidaridad (26).

En Jerez, el día 11 habían dejado de trabajar los distintos talleres de Artes Gráficas; quedándose la ciudad sin periódicos; y dos días después -el 13 de septiembre-, cuando se declara la huelga general, el gobernador civil responde con la inmediata clausura de todos los centros obreros y las primeras detenciones (27). El ambiente urbano estaba totalmente alterado por los efectos del conflicto. La feria, que por entonces se celebraba, apenas si tenía animación, las corridas de toros tienen que ser suspendidas y el tránsito rodado estaba totalmente paralizado, puesto que sólo de vez en cuando unos camiones cruzaban las principales calles, cargados de botas, conducidos por soldados y custodiados por el Ejército o la Guardia Civil. La imagen que retrataba la prensa de Cádiz,

(26) DC (14-IX-1934), edición de tarde.

(27) DC (13-IX-1934), edición de tarde. 
la única fuente que nos queda para seguir la huelga, no podía ser más expresiva:

«... en el silencio de una ciudad que parece muerta, sólo parece escucharse el murmullo de los que deambulan, de los que van de acá para allá, lentos en el caminar como si arrastrasen los pies» (28).

Algunas informaciones de otros periódicos incluso escribían de una ciudad tomada militarmente por la Guardia Civil, cosa que desmentía el gobernador.

El 14 de septiembre la huelga llega a los panaderos, que son secundados por sus compañeros de San Fernando y la propia capital, Cádiz. La reacción de Luis de Armiñán no se hizo esperar: ordenaba clausurar la sociedad de panaderos y la detención de su junta directiva, a la vez que entraba en contacto con las autoridades militares de Intendencia, para prevenir los posibles problemas de abastecimiento que se pudieran producir.

Asimismo, continuaban llegando trabajadores buscados por los propietarios en los pueblos de la sierra gaditana para realizar la vendimia: 200 aparecían el sábado 14, y otros 200 el lunes siguiente.

Por fin, el 18, la CNT declaraba la huelga general en toda la provincia, siendo secundada masivamente en las principales poblaciones de la Bahía -El Puerto de Santa María, Cádiz y San Fernando- y en otras poblaciones de implantación cenetista, con múltiples incidentes: robo de pan a los repartidores, tiroteos callejeros, detenciones de dirigentes sindicales, explosión de dos petardos en Cádiz, intento de asalto a la casa del propietario y político radical Fermín Aranda, etcétera.

En vista de la situación, un diputado jerezano a Cortes, de la CEDA, Manuel García Atance, se presentaba al alcalde de Jerez para ofrecerle los servicios de las Juventudes de Acción Popular (JAP), incluso "para la recogida de basuras" (29). Y es que había tanta suciedad en las calles jerezanas, que para el corresponsal del "Diario de Cádiz», algunos barrios parecían "más bien aduars marroquíes" (30).

En días sucesivos, los incidentes vuelven a reproducirse: en la Alameda de las Angustias se le prende fuego al coche de Fermín Aranda, que arrastraba un lägo boicot de los horticultores, grupos de jóvenes destrozaban con piedras el alumbrado público, era detenida por orden

(28) DC (15-IX-1934), edición de tarde.

(29) DC (21-IX-1934). Falta la prensa de los días 19 y 20 por la huelga general.

(30) DC (22-IX-1934), edición de tarde. 
gubernativa la joven María Luisa Cobos, apodada «La Comunista», y se clausuraba la imprenta del periódico "El Martillo»; órgano de la sociedad de toneleros.

En este contexto de crispación, no faltaba la nota picaresca. Así la contaba un suplemento de "Claridad" aparecido el día 24 de septiembre, rompiendo la huelga e impreso fuera de Jerez:

«Un pintor, natural de Madrid y otro individuo (...) fueron detenidos en la Corredera, porque pedían limosnas para los hijos de los huelguistas, gastándose en vino lo recaudado. Un grupo de obreros que se dio cuenta de la maniobra, propinó al pintor una paliza que le produjo lesiones en el ojo izquierdo. Después de asistido pasó a la Comisaría y de allí a la cárcel por ser sospechoso e indocumentado".

Y mientras que el día 22 de septiembre ya iban finalizando las huelgas generales declaradas cuatro días antes, el 23 se produce una segunda oleada en solidaridad con los obreros jerezanos: hay huelga general en Sanlúcar, Algeciras, Paterna y La Línea y vuelve a El Puerto de Santa María, donde resulta detenido todo el comité de huelga (31).

La resistencia patronal, dispuesta ya a dar un escarmiento a los huelguistas radicaliza las posiciones de éstos, provocando la proliferación de actos más o menos violentos: se apedrean lunas de escaparates y automóviles (32), se incendian pajares en el campo (33), hay un intento de incendio de un camión cargado de muebles, un esquirol resulta herido por los disparos de un piquete y se arrojan botellas de líquidos inflamables sobre dos bodegas de la ciudad (34), lo que daba pie a "Claridad" a denunciar, en su breve reaparición, «la llegada a Jerez de pistoleros profesionales dispuestos a sacrificar bárbaramente vidas humanas" (35).

Ante la gravedad de la situación, la actitud del alcalde, el radical Juan Narváez, no podía ser más pasiva y la inestabilidad del Ayuntamiento, mayor por la declaración de incompatibilidad efectuada por el gobernador sobre algunos concejales republicanos (36) y por la reincorporación a sus puestos de los concejales monárquicos, suspendidos de

(31) DC (26-IX-1934), edición de tarde.

(32) DC (27-IX-1934), edición de mañana.

(33) DC (27-IX-1934), edición de tarde.

(34) DC (1-X-1934), edición de tarde.

(35) "Claridad". Semanario informativo de Jerez (24-IX-1934).

(36) Entre ellos, los dos primeros alcaldes republicanos de Jerez. 
sus funciones con motivo de la "Sanjurjada» del 10 de agosto de 1932 y sus complicidades con el frustrado movimiento rebelde.

La salida de los concejales republicanos y la éntrada de los "gremiales» o monárquicos, propiciadas desde el Gobierno Civil - significativas del cambio que se estaba operando en los centros de poder del aparato del Estado-, se convierten en los principales temas de debate de las sesiones municipales que se celebran mientras duraba la huelga, mostrándose el Ayuntamiento totalmente de espaldas a lo que ocurría en la calle.

Sólo un mes después de estallar el conflicto y antes de que empezara a debatirse el orden del día de la sesión del 15 de septiembre, el concejal socialista José Almagro pedía la palabra, para solicitar la presencia en la ciudad del gobernador civil — «interesando que dé la cara" (37), que se entrevistara con las partes afectadas "y se pongan de acuerdo para solucionar el conflicto".

A la semana, ante la indiferencia del alcalde, dos concejales republicanos solicitaban su intervención para mediar en la huelga, alegando la primera autoridad local que las gestiones las estaba realizando el gobernador y que había que esperar sus resultados.

El 29 de septiembre, en una nueva sesión, otro concejal republicano -en el turno de ruegos y preguntas al final de la misma - volvía a pedir la mediación del alcalde, convocando una asamblea de patronos y obreros. La respuesta de Juan Narváez volvía a ser la misma: él no hacía nada porque "el Sr. Gobernador continúa sus gestiones».

Por fin, terminando septiembre, se reunían en el Gobierno Civil de Cádiz representantes de arrumbadores y patronos durante varias horas sin que se alcanzara ningún acuerdo. Mientras los primeros reiteraban que sólo trabajarían en las bodegas con los cajones de envases fabricados en Jerez, la patronal, representada por la Asociación Gremial de Exportadores de Vinos, pedía la reincorporación al trabajo de los obreros, antes de emprender cualquier negociación y, a continuación, intenta romper la huelga contratando arrumbadores de forma individualizada a razón de 7,25 pesetas diarias de salario (38).

Por este motivo y para seguir resistiendo, los huelguistas decidían enviar sus hijos a Ubrique y Sanlúcar, a las casas de sus compañeros que se habían ofrecido para asistirlos y alimentarlos. Sin embargo, el gobernador civil, en su estrategia de «arrinconamiento», para acabar con la re-

(37) Archivo Municipal de Jerez de la Frontera. Actas Capitulares. Sesiónn del 15 de septiembre de 1934, p. 184.

(38) DC (30-IX-1934). 
sistencia obrera, suspende esta salida, después de un contacto con el alcalde radical y la patronal, ofreciendo como alternativa la asistencia de comidas en las casas benéficas provinciales, con el argumento de que no toleraba que se hiciera "política y propaganda con los niños" (39). El alcalde incluso proponía, que las comidas de beneficencia para estos niños estuviesen costeadas por la Comisión Ejecutiva de la Asociación Gremial de Criadores y Exportadores de Vinos (!), esto es, la misma patronal contra la que había comenzado el conflicto de los arrumbadores.

Sin salida negociada posible, un acontecimiento externo decisivo para la historia de la Segunda República española -la declaración de huelga general en todo el país al entrar la CEDA en el Gobierno y el octubre asturiano- va a provocar la derrota definitiva de las organizaciones obreras jerezanas.

La proclamación del estado de guerra en toda España y en la provincia de Cádiz traspasa los poderes sobre el orden público del gobernador civil al militar. Se declara la clausura de todos los centros políticos progresistas, incluida la del Círculo Republicano Conservador y se suspende a todos los Ayuntamientos gaditanos de mayorías de izquierdas. En la capital de la provincia, el 7 de octubre, las Asociaciones $\mathrm{Pa}$ tronales Gaditanas, por medio de un telegrama enviado a Lerroux, ponían incondicionalmente a disposición del Gobierno "todos sus automóviles y camiones, así como la prestación personal de sus asociados técnica y profesionalmente para ir allí donde las fuerzas demanden a fin de normalizar hasta donde sea posible la vida de la Patria” (40).

Al día siguiente, una Comisión de Acción Ciudadana, la coalición de las derechas monárquicas gaditanas, presidida por el diputado tradicionalista Miguel Martínez de Pinillos, visitaba al general Mena, gobernador militar, para "expresarle su más enérgica protesta por la traidora actitud del Gobierno de Cataluña y demás criminales perturbadores del orden público, así como su más entusiasta adhesión al Ejército".

Con este ambiente, el 10 de octubre reaparecía "El Guadalete», sin publicarse desde el 11 de septiembre. El titular de su editorial era harto significativo: "iiViva España!!». Era evidente que los trabajadores jerezanos habían perdido esta batalla, y sólo les quedaba -como hicieronla reincorporación a sus lugares de trabajo.

(39) DC (4-X-1934), edición de tarde.

(40) DC (8-X-1934), edición de tarde. 